\title{
Population Health and COVID-19 in Canada: a Demographic Comparative Perspective
}

\author{
Daniela Ghio ${ }^{1}$ - Enrique Acosta ${ }^{2}$ - David Fisman ${ }^{3}$. Andrew Noymer ${ }^{4}$. \\ Nikolaos I. Stilianakis ${ }^{1,5} \cdot$ Simona Bignami-Van Assche ${ }^{6}$
}

Received: 30 August 2021 / Accepted: 31 August 2021 / Published online: 22 September 2021

(c) The Author(s), under exclusive licence to Springer Nature Switzerland AG 2021

Demographers have been at the forefront of academic research about the burden of new coronavirus disease (COVID-19). Since the early work of Dowd et al. (2020), demographic research has identified the role of population age structure for understanding levels and differentials of COVID-19 fatality (Dudel et al., 2020; Medford \& Trias-Llimòs, 2020). This is because the age gradient of COVID19 mortality is at least as steep as that of all-cause mortality, causing a greater concentration of deaths in old age (Goldstein \& Lee, 2020; Guilmoto, 2020). Sex differentials in COVID-19 mortality are also more pronounced than all-cause mortality: COVID-19 mortality rates of men aged 25-80 have been found to be greater than those of women (Geldseltzer et al., 2021; Guilmoto, 2020), because of a combination of biological and behavioral factors (Cai, 2020; Falahi and Kenarkoohi, 2020; Gebhard et al., 2020; Klein et al., 2020; Scully et al., 2020; Takahashi et al., 2020). Finally, by recognizing the role of basic demographic characteristics for COVID-19 severe outcomes, demographers have directly contributed to improvements in data collection (Riffe et al., 2021), and the evaluation of existing data sources for mortality analysis (Garcia et al., 2021). These contributions complemented epidemiological assessments of COVID-19 and demonstrated the importance of including demographic features in research about the pandemic.

Canada has been largely absent from comparative demographic studies about COVID-19 mortality and morbidity (Bignami, in this issue). In this Editorial, we

Daniela Ghio

daniela.ghio@ec.europa.eu

1 European Commission Joint Research Center, Ispra, Italy

2 Max Plank Institute for Demographic Research, Rostock, Germany

3 Della Lana School of Public Health - University of Toronto, Toronto, Canada

4 University of California - Irvine, Irvine, CA, USA

5 Department of Biometry and Epidemiology, University of Erlangen-Nuremberg, Erlangen, Germany

6 Université de Montréal, Montreal, Canada 
thus attempt to put Canada's pandemic experience in context. Recent demographic research has focused on excess mortality attributable to COVID-19 (for instance: Garcia-Guerrrero et al., and Decarie and Michaud, in this issue), which is now considered to best represent the full impact of the pandemic since it includes both total COVID-19 mortality as well as mortality indirectly related to the disease (WHO, 2021). Current global estimates of COVID-19 excess mortality are close to 3 million deaths, 1.2 million more than the official count of COVID-19 deaths. ${ }^{1}$ The region of the Americas (that includes Canada, the USA, and Mexico) ${ }^{2}$ accounts for 1.34-1.46 million excess deaths attributable to COVID-19, a figure slightly higher than the corresponding one for the European region (1.11-1.21 million excess deaths). ${ }^{3}$ In Canada, the number of excess deaths is estimated at 18,511 between March 2020 and April 2021 (Statistics Canada, 2021a). However, Canada lags extremely behind other high-income countries in mortality and cause-of-death reporting, which is of provincial responsibility and largely paper-based (Décarie and Michaud, this issue). For instance, as of early June 2021, the province of Manitoba had not yet finished tallying the overall death count for 2020 (Statistics Canada, 2021a), and cause-of-death data was complete only until February 2020-before the pandemic even begun (Moriarty et al., 2021).

Given data limitations for the accurate estimation of excess mortality, comparisons of the case fatality risk (CFR), that is, the ratio of reported deaths to diagnosed infections of severe acute respiratory syndrome coronavirus (SARS-CoV-2), are useful to put the Canadian pandemic experience in context. The CFR has been one of the main indicators used for developing mitigation strategies (including vaccination) and evaluating their effectiveness across countries over the course of the pandemic. International comparisons of COVID-19 CFR have also become important to assess the health burden associated with SARS-CoV-2 mutations.

Estimates of COVID-19 CFR have varied substantially across countries over the course of the pandemic (Rajgor et al., 2020). In part, as studies of other emerging pathogens like Ebola and SARS have shown (Ghani et al., 2005; Lipsitch et al., 2015; Wu et al., 2020); this is due to the delay between symptoms onset, diagnosis, and death or recovery. In the case of COVID-19, an additional source of bias is that a significant proportion of SARS-CoV-2 infections are mild or remain asymptomatic,

\footnotetext{
1 Only 16 of the WHO's 106 member states have sufficient data to calculate excess mortality empirically. Several demographers (including Noymer, Acosta and Bignami) are currently involved in the WHO/UN Technical Advisory Group (TAG), whose work informs mortality assessment underlying estimated presented in the WHO's 2021 World Statistics Report (WHO, 2021) and the UN's 2021 World Population Prospects (to be released in 2022). It is worth noting that, for many countries (representing most of the world's population), there will never be direct, vital-registration based measures of COVID19 mortality and excess mortality, however.

2 The WHO AMR region includes all countries in North, Central, and South America (Antigua and Barbuda, Argentina, Bahamas, Barbados, Belize, Bolivia, Brazil, Canada, Chile, Colombia, Costa Rica, Cuba, Dominica, Dominican Republic, Ecuador, El Salvador, Grenada, Guatemala, Guyana, Haiti, Honduras, Jamais, Mexico, Nicaragua, Panama, Paraguay, Peru, Saint Kitts and Nevis, Saint Lucia, Saint Vincent and the Grenadines, Suriname, Trinidad and Tobago, USA, Uruguay, and Venezuela).

3 The WHO EURO region includes all countries in Western, Eastern, Southern, and Northern Europe as well as the Russian Federation.
} 
and thus avoid detection ( $\mathrm{Li}$ et al., 2020). At the same time, COVID-19 severity increases with age (Goldstein \& Lee, 2020; Green et al, 2020; Guilmoto, 2020), and thus, older individuals are over-represented in epidemiological data (Fisman et al., 2020). These issues are compounded by the fact that countries vary in recording COVID-19 as the cause of death, and accurate cause-of-death data remains incomplete while the pandemic is still unfolding (Garcia et al., 2021; Goldstein \& Lee, 2020).

Dudel et al. (2020) have shown that the age structure of confirmed SARS-CoV-2 infections is an important source of bias in international comparisons of the CFR, as it can account for up to two-thirds of the observed variation in the CFR across countries. To remove the above-mentioned biases in CFR comparisons, demographic studies have followed a classic approach in mortality analysis and relied on direct standardization by age of the CFR (Dowd et al., 2020; Goldstein \& Lee, 2020; Green et al., 2020; Guilmoto, 2020; Sudharsanan et al., 2020). The main disadvantage of age-standardized CFRs is that they vary depending on the choice of the standard population. We thus exploit another demographic tool and compare COVID-19 mortality in Canada and a selected number of countries with a synthetic indicator that removes the effect of differential case ascertainment by age without relying on standardization (Bignami \& Ghio, 2020, 2021). ${ }^{4}$ Comparable data on cases and deaths by age are taken from COVerAGE-DB, one of the few existing databases of official counts of COVID-19 cases and deaths that are standardized and made accessible in harmonized age groups (Riffe et al., 2021).

To avoid spurious comparisons because of the different pace of COVID-19 vaccination starting in January 2021, we limit our focus to the period ending on February 27,2021 , which captures the first and second pandemic wave in the selected countries. As it can be seen in Table 1, the first wave (begun in February 2020 and considered concluded by the end of June 2020) has been, in absolute terms, smaller and less fatal than the second wave (begun in Fall 2020) in all countries considered. During the second wave, the table shows that the number of confirmed COVID19 cases increased approximately geometrically, whereas the number of COVID19-related deaths increased arithmetically. This is predominantly due to expanded testing capacity as the pandemic progressed and also to the younger age profile of

\footnotetext{
${ }^{4}$ This synthetic CFR (SCFR) is obtained by summing over all age groups the age-specific CFRs that apply in a given period and multiplying the sum by the width of the age intervals.
} 
Table 1 Total number of COVID-19 cases and related deaths, and case fatality risk (CFR), by country and pandemic wave

\begin{tabular}{|c|c|c|c|c|c|c|c|c|c|}
\hline \multirow[t]{2}{*}{ Country } & \multicolumn{3}{|l|}{ Cases } & \multicolumn{3}{|l|}{ Deaths } & \multicolumn{3}{|l|}{ CFR } \\
\hline & Wave 1 & Wave 2 & Wave $1+2$ & Wave 1 & Wave 2 & $\begin{array}{l}\text { Wave } \\
1+2\end{array}$ & $\begin{array}{l}\text { Wave } \\
1\end{array}$ & $\begin{array}{l}\text { Wave } \\
2\end{array}$ & $\begin{array}{l}\text { Wave } \\
1+2\end{array}$ \\
\hline Austria & 17,676 & 436,092 & 453,768 & 676 & 7,721 & 8,397 & 3.8 & 1.8 & 1.9 \\
\hline Canada & 103,367 & $1,294,473$ & $1,397,840$ & 8,591 & 16,824 & 25,415 & 8.3 & 1.3 & 1.8 \\
\hline Italy & 240,455 & $2,639,328$ & $2,879,783$ & 33,736 & 61,946 & 95,682 & 14.0 & 2.3 & 3.3 \\
\hline Portugal & 42,489 & 761,803 & 804,292 & 1,579 & 14,738 & 16,317 & 3.7 & 1.9 & 2.0 \\
\hline Spain & 246,424 & $2,889,381$ & $3,135,805$ & 29,375 & 44,481 & 73,856 & 11.9 & 1.5 & 2.4 \\
\hline Sweden & 68,451 & 600,662 & 669,113 & 5,333 & 7,549 & 12,882 & 7.8 & 1.3 & 1.9 \\
\hline USA & $2,504,301$ & $25,781,243$ & $28,285,544$ & 127,170 & 409,508 & 536,678 & 5.1 & 1.6 & 1.9 \\
\hline
\end{tabular}

Wave 1: February 1, 2020, to June 30, 2020. Wave 2: July 1, 2021, to February 27, 2021. CFR (case fatality risk $=$ number of deaths $/$ number of cases $* 100$

Source: COVerAge-DB (Riffe et al., 2021), except Canada (Statistics Canada, 2021b)

COVID-19-related infections and deaths during the second wave compared to the first (Fig. 1).

Once differential case ascertainment by age across countries and between pandemic waves is taken into account, overall differences in COVID-19 fatality across countries are less stark than suggested by the crude CFR, especially for the first pandemic wave. Overall, Canada ranks just below Sweden in terms of COVID-19 fatality at the end of the second wave (Fig. 2), ahead of the USA and Italy. Canada was also among the top three countries where COVID-19 had been most fatal during the first wave, the other two being Italy and Sweden. The age pattern of COVID-19 fatality is not unique, however. In some countries (e.g., Italy), it results from the highest age-specific CFRs between age 50 and 70, whereas in others (notably Sweden and Canada) from the highest age-specific CFRs above age 70. Canada's ranking is noteworthy since most infections and deaths have been concentrated in the provinces of Québec and Ontario in both pandemic waves (Bignami, in this issue). 


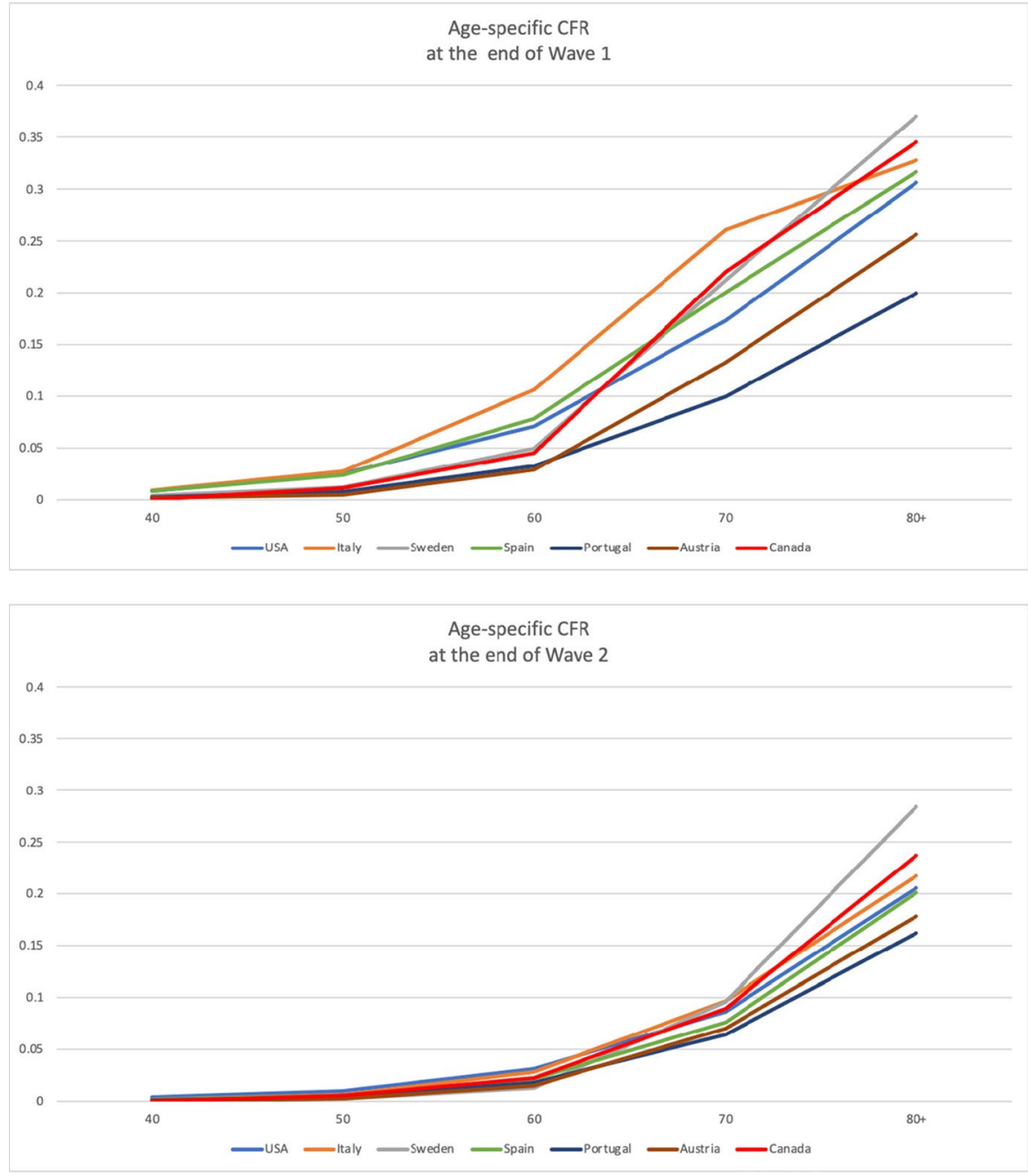

Note: 2: February 27, 2021. Age-specific case-fatality risk at age $x=$ number of COVID-19-related deaths at age $x /$ number of COVID-19 cases at age $x$. Source: COVerAge-DB (Riffe, et al., 2021), except Canada (Statistics Canada, 2021 a,b).

Fig. 1 Age-specific case fatality risk, by pandemic wave and country 


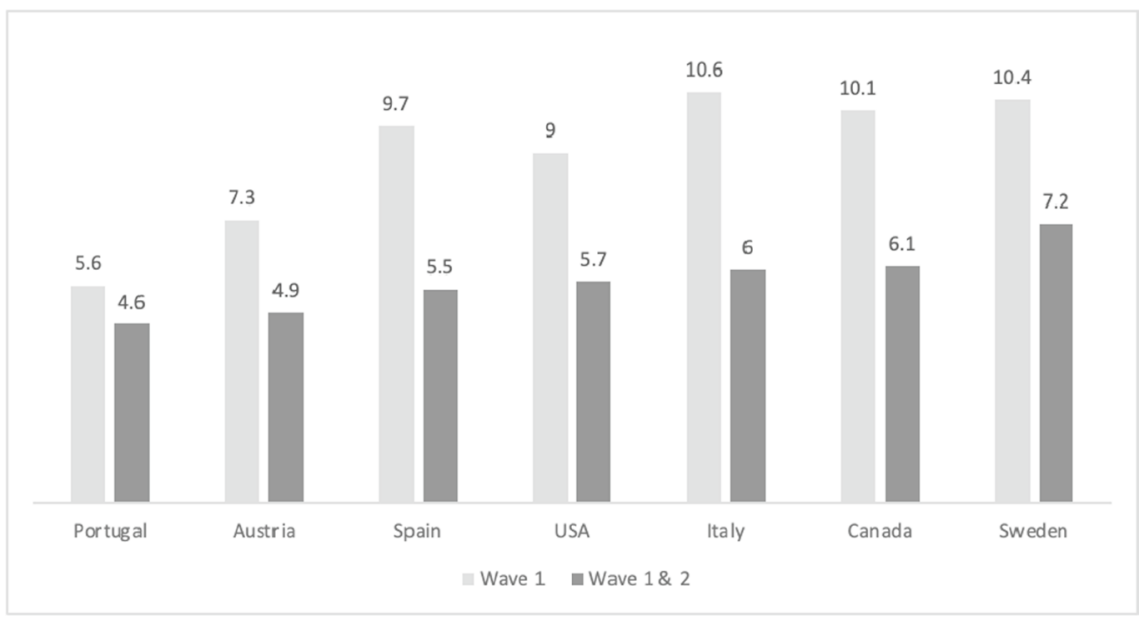

Note: End of wave 1: June 30, 2020; end of wave 2: February 27, 2021. Synthetic casefatality risk (SCFR) calculated as described in Bignami and Ghio (2020). The SCFR measures the average number of deaths per 100 COVID-19 cases. Source: COVerAge-DB (Riffe, et al., 2021), except Canada (Statistics Canada, 2021 a,b).

Fig. 2 Synthetic case fatality risk, by country and pandemic wave. Note: End of wave 1: June 30, 2020; end of wave 2: February 27, 2021. Synthetic case fatality risk (SCFR) calculated as described in Bignami and Ghio (2020). The SCFR measures the average number of deaths per 100 COVID-19 cases. Source: COVerAge-DB (Riffe et al., 2021), except Canada (Statistics Canada, 2021a, b)

\section{Declarations}

Disclaimer The opinions expressed by authors contributing to this journal do not necessarily reflect the opinions of the European Commission or the institutions with which the authors are affiliated.

\section{References}

Bignami, S. and D. Ghio. (2020). A demographic adjustment to improve measurement of COVID-19 severity at the developing stage of the pandemic. medRxiv. https://doi.org/10.1101/2020.03.23. 20040998

Bignami, S. \& D. Ghio. (2021). Comparing COVID-19 fatality across countries: A synthetic demographic measure. Submitted.

Cai, H. (2020). Sex difference and smoking predisposition in patients with COVID-19. Lancet Respiratory Medicine, 8 (4): e20.

Dowd, J. D., Andriano, L., Brazel, D. M., Rotondi, V., Block, P., Ding, X., Liu, Y., \& Mills, M. C. (2020). Demographic science aids in understanding the spread and fatality rates of COVID-19. Proceedings of the National Academy of Sciences, 117(18), 9696-9698.

Dudel, C., Riffe, T., Acosta, E., van Raalte, A., Strozza, C., \& Myrskyla, M. (2020). Monitoring trends and differences in COVID-19 case fatality rates using decomposition methods: Contributions of age 
structure and age-specific fatality. PLOS ONE. https://doi.org/10.1371/journal.pone.0238904;publi shedonlineSeptember1

Falahi, S., \& Kenarkoohi A. (2020) Sex and gender differences in the outcome of patients with COVID-19. Journal of Medical Virology 1-2.

Fisman, D., Greer, A.L., \& Tuite A.R. (2020). Age is just a number: A critically important number for COVID-19 fatality. Annals of Internal Medicine, 173(9): 762-763; published online November 3, 2020.

Garcia, J., Torres, C., Barbieri, M., Camarda, G., et al. (2021). Differences in COVID-19 mortality: Implications of imperfect and diverse data collection systems. Population (english Edition), 76(1), 35-72.

Gebhard, C., Regitz-Zagrosek, V., Neuhauser, H. K., Morgan, R., \& Klein, S. L. (2020). Impact of sex and gender on COVID-19 outcomes in Europe. Biology of Sex Differences, 11(1), 1-13.

Geldseltzer, P., Mukama, T., Jawad N., Riffe T., Rogers A., \& Sudharsanan N. (2021). Sex differences in the mortality rate for coronavirus disease 2019 compared to other causes of death. medRxiv. https:// www.medrxiv.org/content/https://doi.org/10.1101/2021.02.23.21252314v1; published online February $8,2021$.

Ghani, A. C., Donnelly, C. A., D.R. Cox DR, , et al. (2005). Methods for estimating the case fatality ratio for a novel, emerging infectious disease. American Journal of Epidemiology, 52(5), 479-486.

Goldstein, J. R., \& Lee, R. D. (2020). Demographic perspectives on the mortality of COVID-19 and other epidemics. Proceedings of the National Academy of Sciences, 117(36), 22035-22041.

Green, M. S., Peer, V., Schwarz, N., \& Nitzan, D. (2020). The confounded case fatality rates (CFR) for COVID-19 hide more than they reveal- a comparison of age-specific and age-adjusted CFRs between seven countries. PLOS ONE, 15(10), 2020. https://doi.org/10.1371/journal.pone.0241031; publishedonlineSeptember10

Guilmoto C.Z. (2020). COVID-19 death rates by age and sex and the resulting mortality vulnerability of countries and regions in the world. medRxiv. https://doi.org/10.1101/2020.05.17.20097410; published online May 20, 2020.

Klein, S.L., Dhakal S., Ursin R.L., Deshpande S., Sandberg K., \& Mauvais-Jarvis F. (2020). Biological sex impacts COVID-19 outcomes. PLoS Pathogens, 16(6): e1008570.

Li, R., Pei, S., Chen, B., Song, Y., Zhang, T., Yang, W., et al. (2020). Substantial undocumented infection facilitates the rapid dissemination of novel coronavirus (SARS-CoV2). Science, 368(4690), 489-493.

Lipsitch M., C.A. Donnelly, C. Fraser, et al. (2015). Potential biases in estimating absolute and relative case-fatality risks during outbreaks. PLoS Negl Trop Dis, 9(7).

Medford, A., \& Trias-Llimòs, S. (2020). Population age structure only partially explains the large number of COVID-19 deaths at the oldest ages. Demographic Research, 43(19), 533-544.

Moriarty, T., Boczula, A. E., Thind, E. K., Loreto, N., \& McElhaney, J. E. (2021). Excess all-cause mortality during the COVID-19 epidemic in Canada. Royal Society of Canada.

Rajgor D.D., M.H. Lee, S. Archuleta, N. Bagdasarian, and S.C. Quek. (2020). The many estimates of COVID19 case fatality rate. Lancet Infectious Diseases, 20(7): 776-777; published online March 27, 2020.

Riffe T., Acosta E.J., \& the COVerAGE-DB team. (2021). Data resource profile: COVerAGE-DB: A global demographic database of COVID-19 cases and deaths. IJE. Forthcoming.

Scully, E. P., Haverfield, J., Ursin, R. L., Tannenbaum, C., \& Klein, S. L. (2020). Considering how biological sex impacts immune responses and COVID-19 outcomes. Nat Rev Immunol, 20, 442-447.

Statistics Canada. 2021a. Provisional deaths counts and excess mortality, January 2020 to March 2021. The Daily, June 7. Retrieved on July 29, 2021 from: https://www150.statcan.gc.ca/n1/daily-quoti dien/210607/dq210607a-eng.htm

Statistics Canada. (2021b). Preliminary dataset on confirmed cases of COVID-19, Public Health Agency of Canada, 2020-2021. Retrieved on August 7, 2021 from: https:/www150.statcan.gc.ca/n1/en/ catalogue/13260003.

Takahashi, T., Ellingson, M. K., et al. (2020). Sex differences in immune responses that underlie COVID19 disease outcomes. Nature, 588, 315-320.

World Health Organization. (2021). World Health Statistics 2021. World Health Organization.

Wu, J. T., Leung, K., Bushman, M., et al. (2020). Estimating clinical severity of COVID-19 from the transmission dynamics in Wuhan, China. Nature Medicine, 26, 506-510.

Publisher's Note Springer Nature remains neutral with regard to jurisdictional claims in published maps and institutional affiliations. 